\title{
Management of Posterior Urethral Valves about 26 Cases
}

\author{
A. S. Ondziel Opara ${ }^{1,2}$, L. I. P. Ondima ${ }^{1,2,3}$, A. M. Ondongo Atipo ${ }^{1,2}$, C. Boutol Mandavo ${ }^{1,2,3}$, \\ R. B. Banga Mouss',2, Dimi Nyanga',2, P. P. Avala',2, A. W. S. Odzébé1,2*, P. A. Bouya1,2 \\ ${ }^{1}$ Faculty of Health Sciences, Marien Ngouabi University, Brazzaville, Republic of Congo \\ ${ }^{2}$ Urology and Andrology Department, University Hospital Center, Brazzaville, Republic of Congo \\ ${ }^{3}$ Pediatric Surgery Department, University Hospital Center, Brazzaville, Republic of Congo \\ Email: ${ }^{*}$ odzebe_s@yahoo.fr
}

How to cite this paper: Ondziel Opara, A.S., Ondima, L.I.P., Ondongo Atipo, A.M., Boutol Mandavo, C., Banga Mouss, R.B., Nyanga, D., Avala, P.P., Odzébé, A.W.S. and Bouya, P.A. (2021) Management of Posterior Urethral Valves about 26 Cases. Open Journal of Urology, 11, 95-102. https://doi.org/10.4236/oju.2021.113010

Received: September 25, 2018

Accepted: March 27, 2021

Published: March 30, 2021

Copyright $\odot 2021$ by author(s) and Scientific Research Publishing Inc. This work is licensed under the Creative Commons Attribution International License (CC BY 4.0).

http://creativecommons.org/licenses/by/4.0/

\begin{abstract}
Aim: To improve management of the posterior urethral valve (PUV) in children in a hospital environment. Patients and Methods: This was a retrospective descriptive study that covered a sixteen (16) years period, from January 1, 2002 to December 31, 2017, In pediatric surgery and urology departments of our teaching hospital, 26 cases of posterior urethral valve (PUV) were involved. The diagnosis was made by retrograde urethrocystography and micturition, supplemented by ultrasound. Results: During this period, 26 patients $(1.7 \%)$ had a PUV. The mean age of the patients was 73, 2 months with extremes ranging from 6 to 180 months. Fifteen patients consulted for dysuria, 8 for complete retention of urine. Only one patient had a history of rolling the valves to the benign ones. The main complications found were urinary tract infection in 15 children, urolithiasis in 3 children and renal failure in 2 children. Two children had serum creatinine values of 50 and $58 \mathrm{mg} / \mathrm{L}$. The lamination of the posterior urethral valves was performed in all patients. In our series, we had one death from chronic renal failure in a 6-year-old child with a bilateral mute kidney at IVU. Conclusion: The valve diagnosis of the posterior urethra is made late because the diagnosis is still postnatal.
\end{abstract}

\section{Keywords}

Valves, Posterior Urethra, Congenital, CHU, Brazzaville

\section{Introduction}

The posterior urethral valves (PUV) are the most common obstructive uropathies in male children [1]. During the last decades, the diagnosis of PUV has 
made a significant advance, in particular by the early detection of the disease during the prenatal period in western countries [2]. This detection is done by chemical analysis of fetal urine, ultrasound evaluation of fetal urinary tract and indication of uro-MRI [3]. Early diagnosis allows not only early management but also the prevention of deterioration of renal function. Despite these advances, long-term renal and bladder repercussions remain a problem in some children with PUV [4]. Indeed, it remains an important cause of infantile renal insufficiency [5]. In underdeveloped countries, PUV is most often postnatally diagnosed, delaying diagnosis and management, and increasing the risk of developing renal failure [6]. Nowadays, in Congo, there are still few publications on this malformation [7]. That's the reason we proposed to carry out this study in order to contribute to the improvement of PUV in the children's care at the University Hospital Center (CHU) of Brazzaville.

\section{Patients and Methods}

This was a retrospective descriptive study that covered a sixteen (16) years period, from January 1, 2002 to December 31, 2017. It took place in the departments of Pediatric Surgery and Urology-Andrology of the University Hospital Center of Brazzaville. The study population consisted of children who had been cared in both services. Were included patients whom the clinical and paraclinical examinations had allowed to retain the diagnosis of PUV and benefited a management. The variables studied were clinical, paraclinical, therapeutic and evolutionary. Clinical variables were: age, consultation reason, temperature, general condition, abdominal distension; paraclinical variables were done for all patients concerned with: blood count, uroculture, urea and serum creatinine, ultrasound of the urinary tract, urethrocystography. The therapeutic variables were: iterative urethral dilation, vesicostomy, cystolithotomy followed by the pose of double "J" probes. The evolutionary variables were: regular checking up of patients in external consultation with the completion of an ultrasound of the urinary was assessed at 7 days postoperative, 1 month, 3 months, 6 months, and 12 months. We know the duration of hospitalization and the results obtained for each type of treatment. The favorable evolution was pronounced on the basis of the standardization of the Biological constants, the absence of the valves to the urethrocystography of control and the improvement of the clinical signs. The valve diagnosis of the urethra was done on the basis of clinical and paraclinical elements. We were able to collect 26 files during this period. The information was collected from a survey card using data from the service registers, inpatient medical records, operative reports and home visits that supplemented the information from the follow-up booklets.

\section{Results}

Between January 1, 2002 and December 31, 2017, 8113 patients were admitted to the pediatric surgery department and to the urology and andrology department 
of the Brazzaville University Hospital Center. During this period, 26 patients had been treated for a PUV at a frequency of $0.3 \%$. Its incidence was 1.7 cases/year.

The mean age of the patients was 73, 2 months with extremes ranging from 6 and 180 months. We divided the children according to the age group knowing that they come to paediatric surgery until the age of 15 (Figure 1). The oldest patient in our series was 15 years old and he was from the rural area.

In our study, we did not record any posterior urethral valve cases diagnosed as antenatal.

The reason for consultation was dysuria $(\mathrm{n}=15)$, complete retention of urine $(\mathrm{n}=8)$ and abdominal pain $(\mathrm{n}=3)$.

In the physical examination a bladder globe was found in 8 children. The main complication found was urinary tract infection $(n=15)$, urolithiasis $(n=$ 3 ) and renal failure $(\mathrm{n}=2)$.

Two children had serum creatinine values $>58 \mathrm{mg} / \mathrm{L}$. Cytobacteriological examination of the urine was performed in all children and revealed: Escherichia coli $(\mathrm{n}=7)$, Klebsiella $(\mathrm{n}=5)$ and Pseudomonas aeruginosa $(\mathrm{n}=3)$. Ultrasound of the urinary shaft was indicated in all children. The results made it possible to objectify bilateral hydronephrosis and control bladder in 24 children (Figure 2).

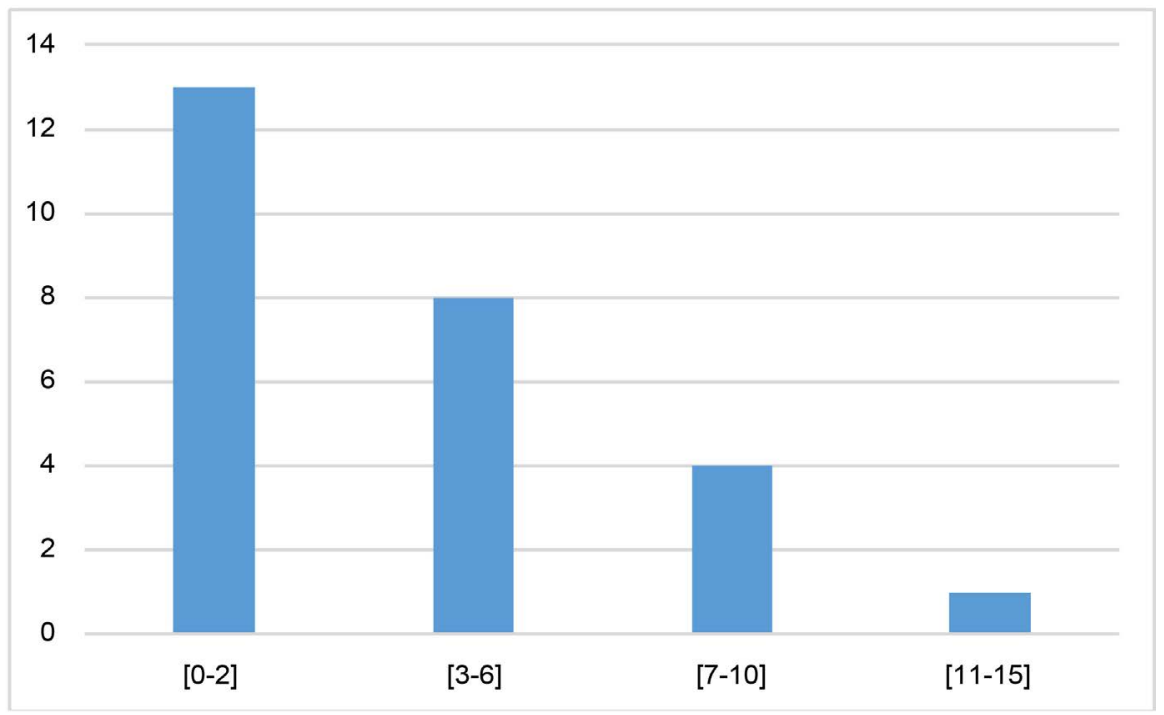

Figure 1. Distribution of patients by age group.
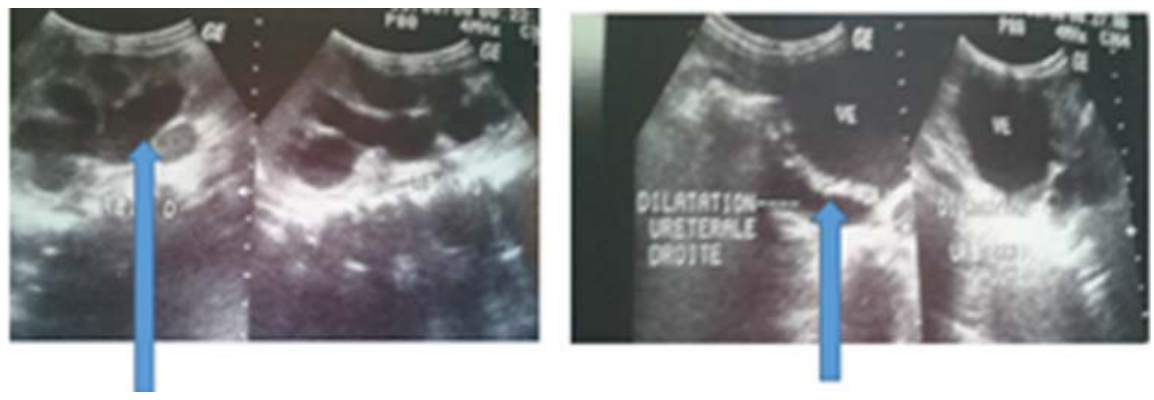

Figure 2. Image 1 and 2 of ultrasonography showing bilateral uretero-hydronephrosis. 
Urethrocystograhy was performed in all children the results were found: a valve association bladder calculus in 14 patients (Figure 3). Urethrocystography shows an image of a bladder diverticula and VUP (Figure 4).

Medical treatment based on antibiotic therapy was indicated in 15 patients with urinary tract infection.

All patients underwent valve with progressive urethral iterative dilatation using probes of increasing caliber. Cysto-lithotomy was indicated in three patients. These were 2 patients with bladder stones and 1 patient with urethral lithiasis

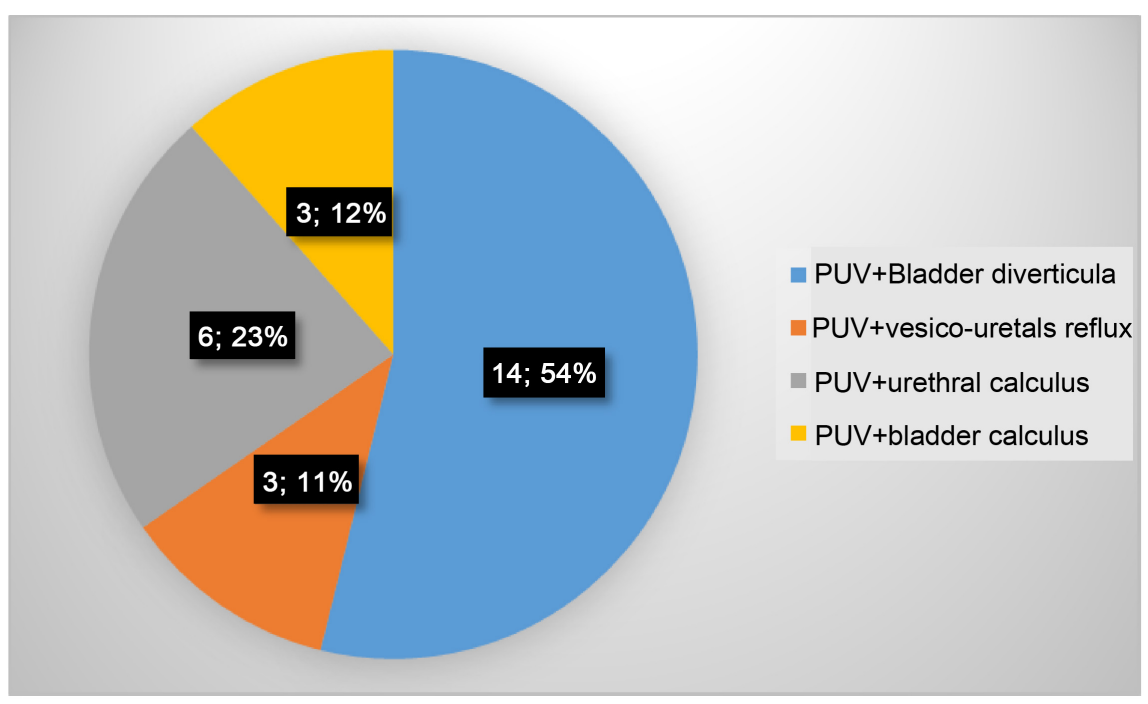

Figure 3. Distribution of children according to the results of the urethrocystography.

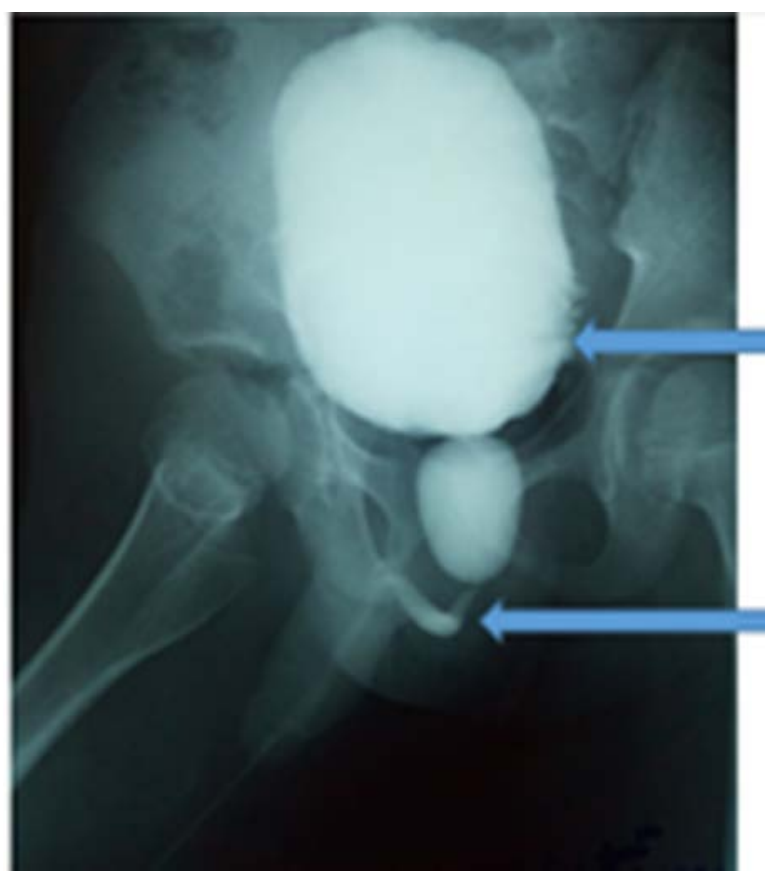

Figure 4. Micturating cystourethrogram showing characteristic "nail clipping" under the dilated prostatic urethra of VUP, Bladder diverticula at the arrow above. 
located at the membranous level. The calculus had been pushed back into the bladder.

In our series, we had one death from chronic renal failure in a 6-year-old child with posterior urethral valves with a bilateral nonfunctional kidney at IVU.

\section{Discussion}

The incidence of PUV is variously reported in the literature; Its incidence is to 1/5000 - 8000 male infants births in the USA [8], 1/8000 births in England [9] and 4/10,000 births in Columbia [10]. Its frequency is unknown in Africa as an evidence to the scarcity of scientific publications [11] [12].

In our study we had 26 cases in 16 years, an incidence of 1.7 cases/year and a frequency of $0.3 \%$. In Senegal [11] frequency to 7 cases/years is an infrequent pathology. They realize a very early onset of bladder obstruction, preventing the normal flow of urine into the posterior urethra and are often accompanied by a bladder control and a vesico-ureteral reflux. Dysuria and urine retention were the main clinical manifestations as in series [8] [10] with varying frequencies. The physical examination revealed a bladder globe in 8 cases/26 (compared to 12 cases/70 in the series presented by Schober in the USA [13]). Makosso et al. [7] in Congo found in 2 cases/3. The antenatal ultrasound not only allows recalling the diagnosis but also especially to carry out a care without prolonged delay after the birth. It has been practiced in the majority of patients of the series American [13], French [14] and Nigerian [6]. A study of North American Pediatric Renal Trials and Collaborative Studies (NAPRTCS) database identified the causes of neonatal end-stage renal disease in the modern era (2000 to 2012) among 98 neonates aged $<31$ days, PUV account for $21 \%$ of the causes of chronic kidney failure in neonatology [15]. Kidney damage can occur early, hence the value of early management.

Other causes in $46 \%$ in our series, no diagnosis was made in antenatal. Urethrocystography was performed in all patients. This is the postnatal reference examination for the detection of posterior urethral valves [16]. These examinations must imperatively include urination phase without probe, in order to highlight the typical image of "nail clipping" at the level of the posterior urethra [17].

The iterative lamination of the urethra by increasing urinary catheters (Fogarty probe, Foley probe) was widely used according to the authors. So Asinobi et al. [6] in Nigeria 15 cases out of 40, Claude et al. [14] in France had treated 32 cases out of 35, Angwofo et al. [18] in Cameroon 15 out of 22. The concern of this technique is that it is done blindly with a risk of false road. Other authors used the Fogarty probe by visualizing the valve with a cystoscopy. It is an alternative to endoscopic valve section. It maintains the minimally invasive transurethral visual standard, and avoids electrocautery and the difficult manipulation of wired electrodes in a constrained field. This hybrid technique is patient friendly, being devoid of radiation exposure, and has the advantage that it can be conducted safely under sedation [19].

Nowadays, the standard treatment of the valves of the posterior urethra is an 
endoscopic section from birth [11] [14]. This technique brings good results. However, it is not yet part of our therapeutic arsenal. The technique with the Fogarty probesau Foley probe has the advantage of being perfectly accessible to practitioners who do not have modern endoscopic equipment. Its success rate is equivalent to the endoscopic route. However, it must be performed with much care attention to avoid urethra's rupture [17]. Our results are identical to those of the series [7] [15] [19].

The postoperative course was simple in all cases, compared to $5.6 \%$ of complications in the series presented by Warren in Canada [20].

We have a case of death in a patient with chronic renal failure. He had arrived very late at the hospital with abdominal pain. The destroying of the valves had been achieved without allowing a recovery of the renal function. Because at this stage the care is multidisciplinary. Il is necessary management involving nephrologists and resuscitators.

Other authors, including Gargah et al. [21] and R. Khemakhema et al. [22] in 46 cases and 71 cases of patients respectively, observed 3 and 6 deaths due to renal failure.

The evolution towards the renal insufficiency is seen in not insignificant proportions. Depending on the series, they can reach up to $45 \%$ of cases.

For these patients, who have reached the end-stage kidney disease, dialysis and/or renal transplantation are required, the cost of management is often expensive, especially when there is not a good system of medical assistance.

Most recent studies have shown that there is no significant difference in prognosis between kidney transplant in relation with PUV and other etiologies [21]. In our context where dialysis and especially renal transplantation are not accessible, prevention and early management remain the only way to avoid reaching the end-renal stage failure.

All these elements lead us to believe that earlier management while improving our technical plateau would allow us to improve our quality of care.

\section{Conclusion}

The PUV is one of the most common obstructive malformative uropathies but infrequent pathology. In our context, the diagnosis is postnatal, delaying its management. It is necessary to make an early diagnosis and to treat the patient precisely because we need to preserve the renal function of the patients. When this pathology is detected late, it can lead to a terminal renal failure. Despite many advances in its management, progressive urethral iterative dilatation using probes of increasing caliber (Fogarty probe or Foley probe) is still used. This technique certainly brings good results but the endoscopic section should be added to our therapeutic arsenal because it is actually the most used technic in the world; it's a gold standard technic.

\section{Conflicts of Interest}

The authors declare no conflicts of interest regarding the publication of this paper. 


\section{References}

[1] Tîrlea, S. and Ionescu, S. (2012) Posterior Urethral Valves-Diagnosis and Primary Treatment Considerations. Chirurgia (Bucur), 107, 218-225.

[2] Hodges, S.J., Pate, B., McLorie, G. and Atala, A. (2009) Posterior Urethral Valves. The Scientific World Journal, 9, Article ID: 923439. https://doi.org/10.1100/tsw.2009.127

[3] Nakai, H., Hyuga, T., Kawai, S., Kubo, T. and Nakamura, S. (2017) Aggressive Diagnosis and Treatment for Posterior Urethral Valve as an Etiology for Vesicoureteral Reflux or Urge Incontinence in Children. Investigative Clinical Urology, 58, S46-S53. https://doi.org/10.4111/icu.2017.58.S1.S46

[4] Kousidis, G., Thomas, D.F., Morgan, H., Haider, N., Subramaniam, R. and Feather, S. (2008) The Long-Term Outcome of Prenatally Detected Posterior Urethral Valves: A 10 to 23-Year Follow-Up Study. BJU International, 102, 1020-1024. https://doi.org/10.1111/j.1464-410X.2008.07745.x

[5] Okafor, H.U., Ekenze S.O. and Uwaezuoke, S.N. (2013) Posterior Urethral Valves: Determinants of Outcome in a Developing Country. Journal of Paediatrics and Child Health, 49, 115-119. https://doi.org/10.1111/jpc.12091

[6] Asinobi, A.O., Gbadegesin, R.A. and Shittu, O.B. (2004) A Review of Cases of Posterior Urethral Valves Seen at the University College Hospital, Ibadan (Nigeria). Medical and Surgical Pediatrics, 26, 430-433.

[7] Makosso, E. and Bouya, A.P. (2005) Diagnosis and Treatment of Posterior Urethra Valves in 3 Observations at Brazzaville University Hospital. Mali Médical, 20, 5-7.

[8] Kumar, S. and Fisk, N.M. (2003) Distal Urinary Obstruction. Clinics in Perinatology, 30, 507-519. https://doi.org/10.1016/S0095-5108(03)00060-5

[9] Malin, G.L., Tonks, A., Morris, R.K. and Kilby, M.D. (2011) Fetal Lower Urinary Tract Obstruction: An Epidemiologogical, Population Based Study of Outcome. Archives of Disease in Childhood Fetal Neonatal, 96.

https://doi.org/10.1136/adc.2011.300160.1

[10] Calderon, S.J. and Zarante, I. (2006) Congenital Urological Anomalies: Epidemiological Description and Associated Risk Factor in Colombia 2001-2004. Archivos Españoles de Urología, 59, 7-14.

[11] Sagna, A., Ndoye, M., Mbaye, P.A., Ngoy, M., Ngom, G. and Fall, I. (2018) Postnatal Endoscopic Resection of Posterior Urethra Valves in Boys: Preliminary Study of 23 Cases. Revue Africaine d'Urologie et d'ndrologie, 1, 409-414.

[12] Kamadjou, C., Rimtebaye, K., Eyongeta, D., Kameni, A., Kamga, J. and Njinou, B. (2018) Management of the Valves of the Posterior Urethra in Urology. Open Journal of Urology, 8, 166-170. https://doi.org/10.4236/oju.2018.85017

[13] Schober, J.M., Dulabon, L.M. and Woodhouse, C.R. (2004) Outcome of Valve Ablation in Late-Presenting Posterior Urethral Valves. BJU International, 94, 616-619. https://doi.org/10.1111/j.1464-410X.2004.05011.X

[14] Claude, B. (2001) Long-Term Results of Primary Avulsion of Posterior Urethra Valves with a Forgaty Probe. Journal d Urologie, 90, 415-417.

[15] Carey, W.A., Martz, K.L. and Warady, B.A. (2015) Outcome of Patients Initiating Chronic Peritoneal Dialysis during the First Year of Life. Pediatrics, 136, e615-e622. https://doi.org/10.1542/peds.2015-0980

[16] Capolicchio, J.P., Braga, L.H. and Szymanski, K.M. (2018) A Practical Guide from the Association of Urologists and Pediatric Urologists of Canada on the Detection and Management of Antenatal Hydronephrosis. Canadian Urological Association 
Journal, 12, 85-92. https://doi.org/10.5489/cuaj.5094

[17] Birraux, J., Gapany, C. and Parvex, P. (2012) The Posterior Urethral Valves. Paediatria, 23, 1-12.

[18] Angwafo, F., Andzé, G., Biouelé, J.M., Sosso, M.A., Edzoa, T. and Niat, G. (1995) The Posteriorurethral Valves in Children: About 22 Cases. Journal d Urologie, 101, 132-137.

[19] Soliman, S.M. (2009) Primary Ablation of Posterior Urethral Valves in Low Birth Weight Neonates by a Visually Guided Fogarty Embolectomy Catheter. The Journal of Urology, 181, 2284-2290. https://doi.org/10.1016/j.juro.2009.01.058

[20] Warren, J., Pike, J.G. and Leonard, M.P. (2004) Posterior Urethral Valves in Eastern Ontario-A 30 Year Perspective. The Canadian Journal of Urology, 11, 2210-2215.

[21] Gargah, T., Gharbi, Y., Moussa, M.B., Kaabar, N. and Lakhoua, M.R. (2010) The Posterior Urethral Valves in Children: About 22 Cases. TunisieMédicale, 88, 557-562.

[22] Khemakhema, R., Ahmed, Y.B., Mefteh, S., Jlidi, S., Charieg, A., et al. (2012) The Posterior Urethral Valves: About 38 Cases. Journal de Pédiatrie et de Puériculture, 25, 242-248. https://doi.org/10.1016/j.jpp.2012.06.006 